ACADEMIA ROMÂNĂ

Revue Roumaine de Chimie

http://web.icf.ro/rrch/
Rev. Roum. Chim.

2021, 66(3), 239-242

DOI: $10.33224 /$ rrch.2021.66.3.03

Dedicated to the memory of

Professor Dumitru OANCEA (1941-2020)

\title{
GAS SORPTION PHENOMENA ON SOLID SURFACES
}

\author{
Niculae I. IONESCU* and Veronica BRĂTAN \\ "Ilie Murgulescu" Institute of Physical Chemistry of the Roumanian Academy, 202 Spl. Independentei, \\ 060021 - Bucharest, Roumania
}

Received July 30, 2020

A model explaining the logarithmic rate law used in adsorption/desorption of gas-solid processes is presented. The association of free surface sites in greater ones can be produced in adsorption processes. The dissociation of these new sites into the initial free sites can be obtained in desorption processes.

$$
\frac{1}{\mathrm{q}}=\frac{\mathrm{Nc}}{\mathrm{ab}} \cdot \ln (\mathrm{at}+\mathrm{d})
$$

\section{INTRODUCTION}

The kinetics of gas sorption phenomena, adsorption or desorption on solid surfaces is mostly described by a logarithmic law. ${ }^{1,2}$ In case of adsorption, the integral form is:

$$
\mathrm{q}=\frac{1}{\mathrm{~b}} \cdot\left[\ln \left(\mathrm{t}+\mathrm{t}_{0}\right)-\ln \mathrm{t}_{0}\right]
$$

This integral form is obtained from two differential forms of equations, namely:

$$
\frac{\mathrm{dq}}{\mathrm{dt}}=\mathrm{a} \cdot \exp (-\mathrm{bq})
$$

or

$$
\frac{\mathrm{dq}}{\mathrm{dt}}=\frac{1}{\mathrm{~b}} \cdot \frac{1}{\mathrm{t}+\mathrm{t}_{0}}
$$

In all these equations (1)-(3) $q$ is the adsorbed gas quantity at the $t$ moment and $\mathrm{t}_{0}=\frac{1}{\mathrm{ab}}$ if $\mathrm{t}=0, \mathrm{q}=0$. ( $a, b$ - constants)
Normally all these laws (1)-(3) where obtained with kinetic models where one active surface site is involved for one gas molecule sorbed. Till now there doesn't exist a general model for the explanation of the logarithmic law used in adsorption-desorption of gases on or from solid surfaces. All the forms of this law presented in equations (1)-(3) have been studied and three classes of models have been proposed: the site number variations, the existence of a variable activation energy and the presence of non-uniform surfaces. ${ }^{3-10}$

In the present paper we intend to discuss the situation when one gas molecule is adsorbed on more than one active site of a solid surface.

\section{THE MODEL}

Let be the adsorption of a gas molecule on a surface which leads to the invalidation not of one active site but more, as it occurs for example in the adsorption of gases on inorganic semiconductors.

\footnotetext{
${ }^{*}$ Corresponding author e-mail: ionescu@icf.ro
} 
The disappearance of more than one free site for a single adsorbed molecule is equivalent with the association of several sites which can act as a single one in the adsorption process.

It can be admitted that the association of sites is given by:

$$
\mathrm{s}=\mathrm{s}(\mathrm{n})
$$

where $s$ is the number of associated free sites and $n$ - the number of single free sites, whose variation is supposed to have the form:

$$
\frac{\mathrm{dn}}{\mathrm{dt}}=\mathrm{g}(\mathrm{n})
$$

where $g(n)$ is an arbitrary function depending only on $n$.

In equation (4) we admit that $s$, which is a free site, acts in the adsorption process as a single one. The variation of $n$ is supposed to have the form (5). The assumptions concerning $g(n)$ and $n=\exp (a t)$, where $\mathrm{a}$ is a constant and $\mathrm{t}-$ the time, are usual in solid-gas reactions.

Supposing the following model for the gas sorption on solid surfaces:

$$
\begin{gathered}
\frac{\mathrm{dq}}{\mathrm{dt}}=\mathrm{Nsq}^{2} \\
\frac{\mathrm{ds}}{\mathrm{dt}}=\mathrm{bs}^{2}
\end{gathered}
$$

where $\mathrm{q}-$ is the quantity of gas, $N$ is the number of events per unit time which are capable of carrying the process forward, but have only a probability $s$ of doing it; and $a, b$ are constants. The evolution of the process is given by the equation (6a). In this new model the adsorption mechanism on single sites is assumed to be valid for the associated sites.

From relation (4) and (5) results:

$$
\frac{\mathrm{ds}}{\mathrm{dt}}=\frac{\mathrm{ds}}{\mathrm{dn}} \cdot \frac{\mathrm{dn}}{\mathrm{dt}}=\frac{\mathrm{ds}}{\mathrm{dn}} \cdot \mathrm{g}(\mathrm{n})
$$

which using equation (6b) leads to:

$$
\mathrm{bs}^{2}=\frac{\mathrm{ds}}{\mathrm{dn}} \cdot \mathrm{g}(\mathrm{n})
$$

or

$$
\frac{\mathrm{ds}}{\mathrm{s}^{2}}=\mathrm{b} \frac{\mathrm{dn}}{\mathrm{g}(\mathrm{n})}
$$

By integration it results:

$$
-\frac{1}{\mathrm{~s}}=\mathrm{b} \cdot \int \frac{\mathrm{dn}}{\mathrm{g}(\mathrm{n})}
$$

If $\mathrm{g}(\mathrm{n})=\mathrm{c} \cdot \mathrm{n}$, where $c$ is a constant, than one obtains:

$$
\mathrm{s}=-\frac{\mathrm{c}}{\mathrm{b}} \cdot \frac{1}{\ln (\mathrm{c} \cdot \mathrm{n})}
$$

Using this last value for $s$ in equation (6a) the result is:

or

$$
\begin{aligned}
& \frac{\mathrm{dq}}{\mathrm{q}^{2}}=-\frac{\mathrm{Nc}}{\mathrm{b}} \cdot \frac{\mathrm{dt}}{\ln (\mathrm{cn})} \\
& -\frac{1}{\mathrm{q}}=-\frac{\mathrm{Nc}}{\mathrm{b}} \cdot \int \frac{\mathrm{dt}}{\ln (\mathrm{cn})}
\end{aligned}
$$

When

$$
\mathrm{n}=\exp (\mathrm{at})
$$

$$
\frac{1}{\mathrm{q}}=\frac{\mathrm{Nc}}{\mathrm{ab}} \cdot \ln (\mathrm{at}+\mathrm{d})
$$

where $\mathrm{d}=\operatorname{lnc}$, is also a constant.

The final result is a logarithmic equation.

The only condition which must be fulfilled by the proposed model is the integrability of function $g(n)$. There are also arbitrary functions $g(n)$ which can be integrated leading to kinetic but complicated models. With this proposed model, different reaction mechanisms could be proposed to be described in their kinetic evolution by the same formalism.

The adsorption of the gas started when the surface is sufficiently clean. If the number of gas molecules on a surface is constant in a Langmuir approximation, then:

$$
\mathrm{q}_{\mathrm{t}}=\mathrm{q}_{\mathrm{a}}+\mathrm{q}_{\mathrm{d}}
$$

where $q_{t}$ is the total gas quantity in a monolayer which could be considered as a constant, $q_{a}$ - the adsorbed gas on the surface and $q_{d}$ - the gas which can be desorbed from the covered surface according to the reaction:

$$
\mathrm{A}_{\mathrm{ads}} \rightleftarrows \mathrm{A}_{\mathrm{des}}
$$

and $q_{a}, q_{d}<q_{t}$

In the case of $q_{a}$ then:

$$
\frac{1}{q_{t}-q_{a}}=\frac{N c}{a b} \cdot \ln (a t+d)
$$

When $t$ increases $\left(q_{t}-q_{a}\right)$ diminishes, the result being an increase of $q_{a}$, the adsorbed gas.

Similarly, considering that the gas is adsorbed on the surface, we obtain, in the case of $q_{d}$ :

$$
\frac{1}{q_{t}-q_{d}}=\frac{N}{a b} \cdot \ln (a t+d)
$$


The increase of time, in this case, means an increase of the desorbed gas. Both processes (adsorption and desorption) of a gas on/from a surface are supposed be in Langmuir layers.

The existence of a number of arbitrary function satisfying the integrability conditions can be one of the reason of the impossibility to propose an adsorption-desorption model only on the basis of fitting the experimental data with the logarithmic law.

In desorption of gases the associated sites became free and can dissociate in free sites. In this case the kinetic model is:

$$
\begin{gathered}
\frac{\mathrm{dq}}{\mathrm{dt}}=\mathrm{Nsq}^{2} \\
\frac{\mathrm{ds}}{\mathrm{dt}}=\mathrm{bs}^{2} \\
\mathrm{~s}=\mathrm{s}(\mathrm{n}) \\
-\frac{\mathrm{dn}}{\mathrm{dt}}=\mathrm{g}(\mathrm{n})
\end{gathered}
$$

where $s$ is the number of associated occupied sites which act in desorption as single sites and $n$ the number of single occupied sites.

Now one obtains as before:

$$
\begin{gathered}
\frac{\mathrm{ds}}{\mathrm{dt}}=\frac{\mathrm{ds}}{\mathrm{dn}} \cdot \frac{\mathrm{dn}}{\mathrm{dt}}=-\frac{\mathrm{ds}}{\mathrm{dn}} \cdot \mathrm{g}(\mathrm{n}) \\
\mathrm{bs}^{2}=-\frac{\mathrm{ds}}{\mathrm{dn}} \cdot \mathrm{g}(\mathrm{n}) \\
-\frac{1}{\mathrm{~s}}=-\mathrm{b} \int \frac{\mathrm{dn}}{\mathrm{g}(\mathrm{n})}
\end{gathered}
$$

when $\mathrm{g}(\mathrm{n})=\mathrm{c} \cdot \mathrm{n}$, with $c-$ constant, then

$$
\frac{1}{\mathrm{~s}}=\frac{\mathrm{b}}{\mathrm{c}} \ln (\mathrm{cn})
$$

Using this last value of $s$ in equation (20a) one obtains:

$$
\frac{\mathrm{dq}}{\mathrm{q}^{2}}=\frac{\mathrm{Nc}}{\mathrm{b}} \frac{\mathrm{dt}}{\ln (\mathrm{cn})}
$$

and if using equation (14) then

$$
-\frac{1}{\mathrm{q}}=\frac{\mathrm{Nc}}{\mathrm{ab}} \cdot \ln (\mathrm{at}+\mathrm{d})
$$

which is also a logarithmic law. The desorption of gas started when the surface is totally covered by gas.
With the same hypotheses expressed by relation (16), when the time $t$ increases one obtains an increase of the adsorption or of the desorption in a reverse matter as in case of equations (18) and (19).

The existence of many models explaining the adsorption or desorption phenomena of gases in contact with solid surfaces, like: the generalized Landsberg's model, ${ }^{11}$ the existence of a surface heterogeneity, ${ }^{12,13}$ the model based on the association of active sites ${ }^{14}$ or the surface charge transfer phenomena at the solid gas inteface, ${ }^{15-21}$ is the reason for the impossibility to propose a model only on the basis of fitting the experimental data with the logarithmic law. It should be also mentioned that in order to claim the existence of a logarithmic rate law in adsorption or desorption phenomena of gas-solid processes the first step is to fit the experimental data over a large range of experimental values.

In order to built a realistic model for a logarithmic rate law of gas adsorption or desorption phenomena on/from solid surfaces one has to identify the relevant elementary steps composing its mechanism. ${ }^{22}$ Many models and mechanisms exist, but probably only few of them can be regarded as realistic. The problem is still open.

\section{CONCLUSIONS}

The logarithmic rate law observed in adsorption or desorption of a monolayer of gases on/from solid surfaces can be described by the same equation in a Langmuir approximation. There are cases when the free sites of the surface are associated in a greater site which act as the single one in gas adsorption. Also these associated sites can return to single free sites by dissociation in gas desorption.

\section{REFERENCES}

1. P. T. Landsberg, J. Chem. Phys., 1955, 23, 1079.

2. V. Bratan and N. I. Ionescu, Rev. Roum. Chim., 2019, 64, 981.

3. C. Aharoni and F. C. Tompkins, Adv. Catalysis, 1970, $20,1$.

4. K. Hauffe and S. R. Morrison, "Adsorption" de Gruyter Verlag, Berlin, 1974, p. 87.

5. P. Fejes, "Contact Catalysis", Z.G. Szabo and D. Kallo (Eds.), Akademiai Kiado, vol.1, Budapest, 1976, p. 223.

6. S. R. Morrison, "The Chemical Physics of Surfaces", Plenum Press, New York and London, 1978, p. 46, 241. 
7. E. I. Segal, C. Iditoiu, N. Doca and D. Fatu, "Cataliza si catalizatori”, Ed. Facla, Timişoara, 1986, p. 40.

8. E. I. Segal, N. I. Ionescu, D. M. Razus and I. N. Salageanu, "Cinetica reactiilor catalitice eterogene", vol. I, Ed. Academiei Române, 1992, p. 87.

9. E. Angelescu and A. Szabo, "Cataliza Eterogena", Ed. Brilliant, București, 1998, p. 103.

10. M. I. Temkin, Adv. Catalysis, 1979, 28, 173.

11. N. I. Ionescu and B. Aurian Blajeni, Rev. Roum. Chim., 1977, 22, 353.

12. N. I. Ionescu, Rev. Roum. Chim., 1980, 25, 663.

13. C. F. Cerofolini, Z. Phys. Chem. (Leipzig), 1978, 259, 1020.
14. N. I. Ionescu, Bulg. Chem. Commun., 1992, 25, 39.

15. N. I. Ionescu, Z. Phys. Chem., Neue Folge, 1978, 109, 95.

16. N. I. Ionescu, Rev. Roum. Chim., 1992, 37, 509.

17. N. I. Ionescu, Rev. Roum. Chim., 1995, 40, 629.

18. N. I. Ionescu and M. Caldararu, Rev. Roum. Chim., 2002, $47,1213$.

19. N. I. Ionescu and M. Caldararu, Rev. Roum. Chim., 2006, $51,521$.

20. N. I. Ionescu and M. Caldararu, Rev. Roum. Chim., 2011, 56,853 .

21. N. I. Ionescu, Surf. Sci., 1976, 61, 294.

22. N. I. Ionescu, Rev. Roum. Chim., 2008, 53, 535. 